University of Nebraska - Lincoln

DigitalCommons@University of Nebraska - Lincoln

Faculty Publications: Department of

Entomology

Entomology, Department of

October 2006

\title{
Acute Contact Toxicity of Oxalic Acid to Varroa destructor (Acari: Varroidae) and Their Apis mellifera (Hymenoptera: Apidae) Hosts in Laboratory Bioassays
}

\author{
Nicholas P. Aliano \\ University of Nebraska-Lincoln \\ Marion D. Ellis \\ University of Nebraska-Lincoln, mellis3@unl.edu \\ Blair D. Siegfried \\ University of Nebraska-Lincoln, bsiegfried1@ufl.edu
}

Follow this and additional works at: https://digitalcommons.unl.edu/entomologyfacpub

Part of the Entomology Commons

Aliano, Nicholas P.; Ellis, Marion D.; and Siegfried, Blair D., "Acute Contact Toxicity of Oxalic Acid to Varroa destructor (Acari: Varroidae) and Their Apis mellifera (Hymenoptera: Apidae) Hosts in Laboratory Bioassays" (2006). Faculty Publications: Department of Entomology. 48.

https://digitalcommons.unl.edu/entomologyfacpub/48

This Article is brought to you for free and open access by the Entomology, Department of at DigitalCommons@University of Nebraska - Lincoln. It has been accepted for inclusion in Faculty Publications: Department of Entomology by an authorized administrator of DigitalCommons@University of Nebraska - Lincoln. 


\title{
Acute Contact Toxicity of Oxalic Acid to Varroa destructor (Acari: Varroidae) and Their Apis mellifera (Hymenoptera: Apidae) Hosts in Laboratory Bioassays
}

\author{
NICHOLAS P. ALIANO, ${ }^{1}$ MARION D. ELLIS, AND BLAIR D. SIEGFRIED \\ Department of Entomology, University of Nebraska, 202 Plant Industry Building, Lincoln, NE 68583-0816
}

J. Econ. Entomol. 99(5): 1579-1582 (2006)

\begin{abstract}
Laboratory bioassays were performed to characterize the acute contact toxicity of oxalic acid (OA) to Varroa destructor (Anderson \& Trueman) and their honey bee hosts (Apis mellifera L.). Specifically, glass-vial residual bioassays were conducted to determine the lethal concentration of $\mathrm{OA}$ for $V$. destructor, and topical applications of $\mathrm{OA}$ in acetone were conducted to determine the lethal dose for honey bees. The results indicate that $\mathrm{OA}$ has a low acute toxicity to honey bees and a high acute toxicity to mites. The toxicity data will help guide scientists in delivering optimum dosages of $\mathrm{OA}$ to the parasite and its host, and will be useful in making treatment recommendations. The data will also facilitate future comparisons of toxicity if mite resistance to OA becomes evident.
\end{abstract}

KEY WORDS Varroa destructor, Apis mellifera, oxalic acid, bioassay, $\mathrm{LD}_{50}$

Varroa destructor (Anderson \& Trueman) (Acari: Varroidae), an obligate ectoparasitic mite of the honey bee, Apis mellifera L. (Hymenoptera: Apidae), feeds on the hemolymph of adult bees and of larvae and pupae in capped brood cells. Severe V. destructor infestation of A. mellifera results in honey bee colony death within 3 to $4 \mathrm{yr}$ of initial infestation (Ritter et al. 1983). In 1987, V. destructor was detected in the United States (Anonymous 1987) and has subsequently spread to most regions of the country. At present, V. destructor is the most serious pest of managed honey bee colonies worldwide (Anderson and Trueman 2000).

Miticides are frequently used to control V. destructor in honey bee colonies, and most beekeepers routinely treat their colonies to reduce mite populations. Mite resistance to fluvalinate (Apistan) and coumaphos (Checkmite+), the two most widely applied chemical treatments, has become a major problem for beekeepers in the United States and Europe. Resistance to the pyrethroid fluvalinate has been documented in the United States (Eischen 1995, 1998; Elzen et al. 1998, 1999; Macedo et al. 2002) and Europe (Milani 1994, Lodesani et al. 1995, Thompson et al. 2002). Similarly, resistance to the organophosphate coumaphos has been reported in the United States (Elzen and Westervelt 2002) and Italy (Lodesani 1996). The lipophilic nature of fluvalinate and coumaphos enables them to accumulate in beeswax combs (Wallner 1999). The risk of hive contamination and the decreased efficacies of current $V$. destructor treatments create a need for alternative control strategies.

Oxalic acid (OA) is widely used for controlling $V$. destructor in Europe and Canada, because of its high

\footnotetext{
${ }^{1}$ Corresponding author, e-mail: naliano@unlserve.unl.edu.
}

efficacy $(>90 \%)$ and low risk of hive contamination (Charrière and Imdorf 2002, Special Supplement 2005). OA is applied to colonies by spraying or trickling a solution of $\mathrm{OA}$ and sugar water over the bees (Charrière and Imdorf 2002) or by evaporating crystals with heat. When trickling OA in Canada, the recommended application per hive is $50 \mathrm{ml}$ of a solution containing $35 \mathrm{~g}$ of OA dihydrate in 1 liter of 1:1 sugar:water (wt:vol). When evaporating OA in Canada (vaporizer method), the recommended application is $2 \mathrm{~g}$ of OA dihydrate per hive (Special Supplement 2005). Although OA provides effective control of $V$. destructor, its mode of action is unknown. Furthermore, only one study has quantified the contact toxicity of OA to V. destructor (Milani 2001), and the contact toxicity of OA to honey bees has not been determined. In short, $\mathrm{OA}$ is extensively used without knowing the basic toxicological properties of the compound to $V$. destructor or A. mellifera.

The objective of this study was to characterize the acute contact toxicity of $\mathrm{OA}$ to $V$. destructor and their honey bee hosts in laboratory bioassays. The results will establish dosage-mortality relationships for populations of both mites and bees that have not been exposed to OA and will be useful in making treatment recommendations. The data also will facilitate future comparisons of toxicity if mite resistance to OA becomes evident.

\section{Materials and Methods}

Collection of $V$. destructor. Adult worker bees were collected from a single, mite-infested colony of Carniolan honey bees located on the University of Ne- 
braska campus in February 2005. The bees from each frame (12 frames total) were shaken through a funnel into a bulk bee box. The bees were then subdivided into six smaller wooden boxes that measured $17.75 \mathrm{~cm}$ in length by $15.25 \mathrm{~cm}$ in width by $10.15 \mathrm{~cm}$ in depth (i.d.). Each box had an 8-mesh screen on one of the 17.75 - by $15.25-\mathrm{cm}$ sides for ventilation and mite collection. A pint jar of sugar water (1:1 by volume) was attached to each box, and the boxes were stored at $15.6^{\circ} \mathrm{C}$ in complete darkness until needed for experimentation (no $>2 \mathrm{~d}$ ).

Mites were harvested from adult bees by applying $18 \mathrm{~g}$ of powdered sugar through the screen of each box (Aliano and Ellis 2005). The boxes were inverted after bees were thoroughly coated with powdered sugar to collect mites $(\approx 30 \mathrm{~s})$. The boxes remained inverted until mite fall ceased ( $\approx 20 \mathrm{~min})$. Approximately 100 viable mites were recovered per cage. The powdered sugar was gently brushed off mites with a fine paint brush before transferring them to 20-ml glass scintillation vials (Wheaton Scientific, Millville, $\mathrm{NJ}$ ) for OA exposure.

Glass-Vial Residual Bioassays for $V$. destructor. Techniques described by Plapp and Vinson (1977) and Macedo et al. (2002) were used for conducting glass-vial residual bioassays. Serial dilutions of OA dihydrate ( $>99 \%$ purity) (The Science Company, Denver, CO) (CAS no. 6153-56-6) in acetone were prepared, and a preliminary range-finding bioassay was conducted to determine at least three concentrations that provided $V$. destructor mortalities $>0$ and $<100 \%$. Seven concentrations of OA in acetone were prepared for the definitive bioassay $(1.0,0.3,0.1,0.03$, $0.01,0.003$, and $0.001 \mathrm{mg} / \mathrm{ml})$. One-half milliliter of each solution was pipetted into four 20 -ml glass scintillation vials for each treatment, including an acetone control. The eight resulting OA concentrations that were tested in the definitive bioassay were $500,150,50$, $15,5,1.5,0.5$, and $0.0 \mu \mathrm{g}$ OA per vial. All vials (32 total) were rolled on their sides under a fume hood to evaporate the acetone while evenly coating the vials with OA. The vials were promptly removed after the acetone had evaporated (4-5 min). Ten mites were gently brushed into each vial, the cap was screwed on tightly, and the vials were placed in a dark incubator for $24 \mathrm{~h}\left(26^{\circ} \mathrm{C}\right.$ and $\left.90 \% \mathrm{RH}\right)$. One vial of 10 mites constituted a replication and four vials (40 mites) were used for each of the eight concentrations. Mite mortality was scored $24 \mathrm{~h}$ later by examining mites under a light microscope. Mites were considered dead if they did not respond to probing with a small paint brush.

Topical Application of OA to Adult Bees. Serial dilutions of OA dihydrate ( $>99 \%$ purity) (The Science Company) (CAS no. 6153-56-6) in acetone were prepared, and a preliminary range-finding bioassay was conducted to determine at least three doses that provided honey bee mortalities $>0$ and $<100 \%$. Twoto 7-d-old bees from C.F. Koehnen \& Sons Inc. (Glenn, CA) were shipped to the University of Nebraska in March 2005 and were used for the rangefinding bioassay. The results from the range-finding bioassay were used to establish the definitive bioassay dosage levels.

The definitive bioassay was conducted in September 2005 by using 2 - to 7 -d-old bees that were obtained from brood frames kept in an incubator. Ten bees were placed in each of 32 Benton mailing cages with queen candy. One cage of 10 worker bees constituted a replication and four cages ( 40 bees) were tested for each treatment. Each cage was randomly assigned to one of the eight treatments, and all 10 bees within a cage received the same treatment. A $200 \mathrm{mg} / \mathrm{ml}$ solution of $\mathrm{OA}$ in acetone was prepared. Honey bees were dosed with $10.0,8.0,4.0,2.0,1.0$, or $0.5 \mu$ l of the $200 \mathrm{mg} / \mathrm{ml}$ stock solution. These doses correspond to $2,000,1,600,800,400,200$, and $100 \mu \mathrm{g}$ OA per bee, respectively. After bees had been anesthetized with $\mathrm{CO}_{2}$ the doses were applied to individual bee abdomens by using a Hamilton microsyringe and repeating dispenser (Hamilton Company, Reno, NV). A 10- $\mu$ l control (acetone only) was included in the bioassay along with a dry control in which bees were anesthetized with $\mathrm{CO}_{2}$ but were not treated with acetone. Bees were held at $21.7 \pm 0.4^{\circ} \mathrm{C}$ and $46.3 \pm 1.5 \% \mathrm{RH}$ in darkness for $72 \mathrm{~h}$ except for brief periods when water was administered to the cages. Bees were provided water twice daily throughout the experiment by brushing the cage screens with several drops of water. Mortality was evaluated 24,48 , and $72 \mathrm{~h}$ after treatment.

Statistical Analysis. Results were analyzed by Probit analysis (Finney 1971) by using the POLO-PC statistical software (LeOra Software 1991), and natural mortality was taken into account. The concentrations used for Probit analysis of mite bioassay data were expressed as micrograms per vial. The doses used for Probit analysis of honey bee bioassay data were expressed as micrograms per bee.

\section{Results}

V. destructor Bioassays. The results for the definitive bioassay are summarized in Table 1 . The natural mortality for the definitive bioassay was $9.7 \pm 3.4 \%$ after $24 \mathrm{~h}$.

Honey Bee Bioassays. Doses of OA $<100 \mu \mathrm{g}$ per bee did not cause significant mortality after $48 \mathrm{~h}$ in the range-finding bioassay. Furthermore, it was impossible to calculate the 24 - and $48-\mathrm{h} \mathrm{LD}_{50}$ values for honey bees tested in the range-finding bioassay because significant mortality did not occur until at least $72 \mathrm{~h}$ posttreatment. Aliquots of a $200 \mathrm{mg} / \mathrm{ml}$ solution of OA in acetone were used to dose honey bees in both the range-finding and definitive bioassays, because solutions $>200 \mathrm{mg} / \mathrm{ml}$ clogged the microsyringe, making it impossible to deliver accurate doses of OA. The results for the definitive bioassay are summarized in Table 1. Only the 10- $\mu$ l acetone control group was used for Probit analysis of the definitive bioassay data, because the $10-\mu$ l acetone control had slightly more mortality than the dry control group. The natural mortality for the definitive bioassay was $4.0 \pm 2.5 \%$ after $48 \mathrm{~h}$. We were unable to calculate a confidence interval for the 
Table 1. Honey bee mortality responses to $\mathrm{OA}$ dihydrate when topically applied to bee abdomens in acetone and $V$. destructor mortality responses in glass-vial residual bioassays

\begin{tabular}{lcccccc}
\hline \hline Mortality & $n$ & Slope $\pm \mathrm{SE}$ & $\mathrm{LD}_{10}(95 \% \mathrm{CL})$ & $\mathrm{LD}_{50}(95 \% \mathrm{CL})$ & $\mathrm{LD}_{90}(95 \% \mathrm{CL})$ & $\chi^{2}$ \\
\hline $\begin{array}{l}\text { Honey bee } \\
24 \mathrm{~h}\end{array}$ & 280 & $2.87 \pm 0.54$ & $564.05(95.22-877.92)$ & $1,575.85(1,087.44-2,962.72)$ & $4,402.6(2,541.78-48,848.75)$ & 6.42 \\
$\quad 48 \mathrm{~h}$ & 280 & $3.96 \pm 0.54$ & $176.68(120.36-225.54)$ & $372.01(306.78-439.88)$ & $783.27(643.5-1,042.56)$ & 3.95 \\
$\begin{array}{l}\text { Mite } \\
24 \mathrm{~h}\end{array}$ & 320 & $2.28 \pm 0.35$ & $1.4(0.63-2.26)$ & $5.12(3.47-7.0)$ & $18.69(13.14-31.7)$ & 1.85 \\
\hline
\end{tabular}

LD values for honey bees are in micrograms per bee; LD values for mites are in micrograms per 20 -ml vial.

$72-\mathrm{h} \mathrm{LD}_{50}$, because all bees in the $2,000,1,600,800$, and $400 \mu \mathrm{g}$ of OA per bee treatments died after $72 \mathrm{~h}$. The estimated 72-h LD $D_{50}$ for honey bees was $194.89 \mu \mathrm{g}$ per bee, based on the 100 and $200 \mu \mathrm{g}$ of OA per bee treatments.

\section{Discussion}

Milani (2001) is the only report that quantifies the toxicity of $\mathrm{OA}$ to $V$. destructor collected from bee brood, where the 24-h median lethal density (OA density expected to cause $50 \%$ mortality) for $V$. destructor collected from bee pupae with white eyes was $1.9 \mu \mathrm{g} / \mathrm{cm}^{2}$ (95\% fiducial limits $\left.=1.49-2.36\right)$. The mites collected from brood were exposed to $\mathrm{OA}$ for $4 \mathrm{~h}$ by placing them on glass disks that were sprayed with solutions of OA. The mites were then transferred to clean glass petri dishes at $32.5^{\circ} \mathrm{C}$ and $75 \% \mathrm{RH}$. Our results indicate that the $24-\mathrm{h} \mathrm{LC}_{50}$ for phoretic mites is $5.12 \mu \mathrm{g}$ per vial. By assuming the area of a single 20 -ml scintillation vial treated with OA was $\approx 20 \mathrm{~cm}^{2}$, the 24-h median lethal density in our study was calculated to be $0.26 \mu \mathrm{g} / \mathrm{cm}^{2}$. One likely reason for the apparent higher toxicity in our study is that Milani exposed mites to $\mathrm{OA}$ for $4 \mathrm{~h}$ versus $24 \mathrm{~h}$ in our bioassays. Furthermore, the previous study used mites collected from brood as experimental material, and we collected mites from adult bees. Differences between mites collected from adults versus brood could have also affected bioassay results. However, we think it is preferable to use phoretic mites for conducting OA bioassays, because OA does not kill mites in brood when applied to a hive.

The mode of action for OA is not completely understood. Our results suggest that OA may exhibit its lethal effects on mites via contact. However, we cannot rule out that some mite mortality was caused by exposure to $\mathrm{OA}$ vapors. We expect that mite mortality resulting from exposure to $\mathrm{OA}$ vapors was minimal because $\mathrm{OA}$ has a low volatility at room temperature (vapor pressure $<0.001 \mathrm{mmHg}$ at $25^{\circ} \mathrm{C}$; melting point of $101-102^{\circ} \mathrm{C}$ ) (Merck Index 1996). Charrière and Imdorf (2002) reported that OA mixed in 2:1 sugar water exhibits greater miticidal effectiveness than solutions with half as much sugar. They also demonstrated that increasing the sugar content increased toxicity to bees. Furthermore, Milani (2001) indicates that sucrose and glycerol are synergists of $\mathrm{OA}$ under laboratory conditions, because of sucrose's ability to cause OA to become more hygroscopic. Perhaps the sugar water solution adheres better to bees, thus increasing mite exposure to $\mathrm{OA}$.

The $400,800,1,600$, and $2,000 \mu \mathrm{g}$ per bee doses applied in the definitive bioassay completely covered the bees' abdomen with OA crystals. Furthermore, the $2,000 \mu \mathrm{g}$ per bee dose that was delivered in $10 \mu \mathrm{l}$ of acetone completely soaked the bees with some runoff. Our results indicate that it is nearly impossible to kill $100 \%$ of a test population of adult bees in $24 \mathrm{~h}$ by topically applying $\mathrm{OA}$ in acetone. We conclude that OA has a relatively low acute toxicity to honey bees. There are several accounts in the literature of increased adult bee mortality as a result of $\mathrm{OA}$ application within hives (Charrière and Imdorf 2002, Imdorf and Charrière 1998), suggesting that OA may not exhibit its lethal effect on honey bees until $>24 \mathrm{~h}$ after exposure.

A typical honey bee colony in the North Central region of the United States has a November adult bee population of 35,000 bees (unpublished data). According to the Canadian protocol (Special Supplement 2005), a beekeeper would apply a maximum of $2 \mathrm{~g}$ of OA per hive for $V$. destructor treatment (trickle or vaporizer methods). The resulting dose of OA per bee would have a maximum value of $57.1 \mu \mathrm{g}$ per bee $(2,000,000 \mu \mathrm{g}$ of OA per 35,000 bees $)$. Results from acute exposure bioassays suggest that $57.1 \mu \mathrm{g}$ per bee is considerably below the $48-\mathrm{h} \mathrm{LD}_{10}$ (176.68 $\mu \mathrm{g}$ per bee). Our results showed that all bees dosed with $2,000,1,600,800$, or $400 \mu \mathrm{g}$ of OA per bee died after $72 \mathrm{~h}$. Bees subjected to the $100 \mu \mathrm{g}$ of OA per bee dose survived longer than $72 \mathrm{~h}$ and had mortality similar to the control treatment. Our results roughly coincide with the recommended dose of OA per hive $(\leq 2 \mathrm{~g})$, because doses $\leq 100 \mu \mathrm{g}$ of OA per bee in our laboratory bioassays did not cause significant mortality.

Our data are significant because they quantify the dosage-mortality relationships for populations of both mites and bees that have not been exposed to OA. Our data will facilitate future comparisons of toxicity if mite resistance to OA becomes evident. Furthermore, these basic toxicological properties of the compound will help guide scientists in developing techniques for delivering optimum dosages to the parasite and its host.

\section{Acknowledgments}

We thank Bob Roselle for helping collect varroa mites and for quantifying honey bee mortality. Funding for this re- 
search was provided by an Environmental Protection Agency regional Pesticide Environmental Stewardship Program grant. Additional funding was provided by the Iowa and Wisconsin Beekeepers Associations. This is paper number 15145 of the journal series of the Agricultural Research Division, University of Nebraska-Lincoln.

\section{References Cited}

Aliano, N. P., and M. D. Ellis. 2005. A strategy for using powdered sugar to reduce varroa populations in honey bee colonies. J. Apic. Res. 44: 54-57.

Anderson, D. L., and J.W.H. Trueman. 2000. Varroa jacobsoni (Acari: Varroidae) is more than one species. Exp. Appl. Acarol. 24: 165-189.

Anonymous. 1987. Varroa mites found in the United States. Am. Bee. J. 127: 745-746.

Charrière, J. D., and A. Imdorf. 2002. Oxalic acid treatment by trickling against Varroa destructor: recommendations for use in central Europe and under temperate climate conditions. Bee World 83: 51-60.

Eischen, F. 1995. Varroa resistance to fluvalinate. Am. Bee. J. 135: 815-816.

Eischen, F. A. 1998. Varroa's response to fluvalinate in the western U.S. Am. Bee. J. 138: 439-440.

Elzen, P. J., and D. Westervelt. 2002. Detection of coumaphos resistance in Varroa destructor in Florida. Am. Bee J. 142: 291-292.

Elzen, P. J., F. A. Eischen, J. B. Baxter, J. Pettis, G. W. Elzen, and W. T. Wilson. 1998. Fluvalinate resistance in Varroa jacobsoni from several geographic locations. Am. Bee J. 138: $674-676$.

Elzen, P. J., F. A. Eischen, J. R. Baxter, G. W. Elzen, and W. T. Wilson. 1999. Detection of resistance in US Varroa jacobsoni Oud. (Mesostigmata: Varroidae) to the acaricide fluvalinate. Apidologie 30: 13-17.

Finney, D. J. 1971. Probit analysis. Cambridge University Press, London, United Kingdom.

Imdorf, A., and J. D. Charrière. 1998. Wie Können dir resistenten Varroamilben unter der Schadenschwelle gehalten werden? Schweiz. Bienen-Ztg. 121: 287-291.
LeOra Software. 1991. POLO-PC: a user's guide to probit or logit analysis. LeOra Software, Berkley, CA.

Lodesani, M. 1996. Variabilità dell' efficacia terapeutica ottenuta con trattamento di Perizin. L'ape Nostra Amica. 18: 5-9.

Lodesani, M., M. Colombo, and M. Spreafico. 1995. Ineffectiveness of Apistan ${ }^{\circledR}$ treatment against the mite Varroa jacobsoni Oud. in several districts of Lombardy (Italy). Apidologie 26: 67-72.

Macedo, P. A., M. D. Ellis, and B. D. Siegfried. 2002. Detection and quantification of fluvalinate resistance in Varroa mites in Nebraska. Am. Bee. J. 142: 523-526.

Merck Index. 1996. The Merck Index. Merck \& Co., Inc., Whitehouse Station, NJ.

Milani, N. 1994. Possible presence of fluvalinate-resistant strains of Varroa jacobsoni in northern Italy, p. 87. In A. Matheson [ed.], New perspectives on Varroa. IBRA, Cardiff, United Kingdom.

Milani, N. 2001. Activity of oxalic acid and citric acids on the mite Varroa destructor in laboratory assays. Apidologie 32: $127-138$.

Plapp, F. W., and S. B. Vinson. 1977. Comparative toxicities of some insecticides to the tobacco budworm and its ichneumonid parasite (Campoletis sonorensis). Environ. Entomol. 6: 381-384.

Ritter, W., F. Perschil, and R. Hövell. 1983. Erkennen der Varroatose mit einfachen Untersuchungsmethoden. Allg. Dtsche. Imkerztg. 17: 221-222.

Special Supplement. 2005. Conditions of use for oxalic acid dihydrate for control of varroa mites in honey bee colonies. Hivelights 18 (http://www.honeycouncil.ca/users/ folder.asp?FolderID $=5204$ ).

Thompson, H. M., M. A. Brown, R. F. Ball, and M. H. Bew. 2002. First report of Varroa destructor resistance to pyrethroids in the UK. Apidologie 33: 357-366.

Wallner, K. 1999. Varroacides and their residues in bee products. Apidologie 30: 235-248.

Received 10 March 2006; accepted 2 June 2006. 
This article is the copyright property of the Entomological Society of America and may not be used for any commercial or other private purpose without specific written permission of the Entomological Society of America. 